\title{
Parameters for successful nonoperative management of traumatic aortic injury
}

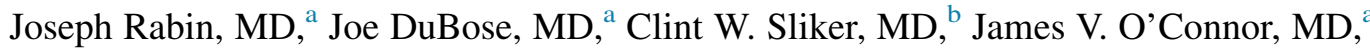 \\ Thomas M. Scalea, MD, ${ }^{a}$ and Bartley P. Griffith, MD
}

\begin{abstract}
Objective: Blunt traumatic aortic injury is associated with significant mortality, and increased computed tomography use identifies injuries not previously detected. This study sought to define parameters identifying patients who can benefit from medical management.
\end{abstract}

\begin{abstract}
Methods: We reviewed 4.5 years of blunt traumatic aortic injuries. Injury was classified as grade I (intimal flap or intramural hematoma), II (small pseudoaneurysm $<50 \%$ circumference), III (large pseudoaneurysm $>50 \%$ circumference), and IV (rupture/transection). Secondary signs of injury included pseudocoarctation, extensive mediastinal hematoma, and large left hemothorax. Follow-up, including computed tomography, was reviewed.
\end{abstract}

Results: We identified 97 patients: 31 grade I, 35 grade II, 24 grade III, and 7 grade IV; 67(69\%) male; mean age $47 \pm 18.8$ years, mean Injury Severity Score $38.8 \pm 14.6$; overall survival $76(78.4 \%)$. Secondary signs of injury were found in 30 patients. Overall, $52(53.6 \%)$ underwent repair, 45 undergoing thoracic endovascular aortic repair, with $2(2.22 \%)$ procedure-related deaths, and 7 undergoing open repair. Five patients undergoing thoracic endovascular aortic repair required 7 additional procedures. In 45 medically managed patients, there were 14 deaths $(31 \%)$, all secondary to associated injuries. Injury Severity Scores of survivors and nonsurvivors were $33 \pm 10.8$ and $48.6 \pm 12.8$, respectively $(P<.001)$. Follow-up showed resolution or no change in $21(91 \%)$ and a small increase in 2 grade I injuries.

Conclusions: All blunt traumatic aortic injury does not necessitate repair. Stratification by injury grade and secondary signs of injury identifies patients appropriate for medical management. Grade IV injury necessitates emergency procedures and carries high mortality. Grade III injury with secondary signs of injury should be urgently repaired; patients without secondary signs of injury may undergo delayed repair. Grade I and II injuries are amenable to medical management. (J Thorac Cardiovasc Surg 2014;147:143-50)

The natural history of blunt traumatic aortic injury (BTAI) was described in a landmark article by Parmley and colleagues ${ }^{1}$ defining early operative repair, often with cardiopulmonary bypass, as the standard of care. ${ }^{1}$ This strategy, however, was associated with significant morbidity and mortality. Alternative management strategies have evolved, including medical management, delayed operative repair, and thoracic endovascular aortic repair (TEVAR).

BTAI is a spectrum from minimal to severe injury. Because of the increased resolution of the newer generation of computed tomographic (CT) scans, the initial trauma evaluation can now identify aortic injuries that previously would have not been detected. In multiply injured patients, BTAI

\footnotetext{
From the R Adams Cowley Shock Trauma Center, ${ }^{a}$ Department of Radiology and Nuclear Medicine, ${ }^{\mathrm{b}}$ and Division of Cardiac Surgery, ${ }^{\mathrm{c}}$ University of Maryland School of Medicine, Baltimore, Md.

Disclosures: Authors have nothing to disclose with regard to commercial support.

Read at the 93rd Annual Meeting of The American Association for Thoracic Surgery, Minneapolis, Minnesota, May 4-8, 2013.

Received for publication May 6, 2013; revisions received July 30, 2013; accepted for publication Aug 15, 2013

Address for reprints: Joseph Rabin, MD, University of Maryland School of Medicine, Shock Trauma, 22 South Greene St, Baltimore, MD 21201 (E-mail: jrabin1@umm. edu).

$0022-5223 / \$ 36.00$

Copyright (c) 2014 by The American Association for Thoracic Surgery

http://dx.doi.org/10.1016/j.jtcvs.2013.08.053
}

may not be an isolated finding but rather associated with other significant, potentially life-threatening injuries. In these patients the treatment and the timing of operative intervention if indicated must be considered in light of the associated injuries. Treatment of BTAI may be of relatively low priority and best delayed until other injuries have been stabilized.

A number of grading systems for BTAI exist. It would be ideal if the grade of injury were related to injury severity and predicted the need for therapy. This study therefore sought to define a clinically useful grading system for BTAI and demonstrate its use to guide therapy.

\section{MATERIALS AND METHODS}

The institutional review board of the University of Maryland approved this retrospective study. All patients admitted with BTAI to the University of Maryland Shock Trauma Center between June 2007 and December 2011 were identified through the trauma registry. Exclusion criteria included age younger than 15 years, arrival in extremis precluding imaging, and initial operation at another facility with subsequent transfer. Medical records, imaging, and operative reports were reviewed. Demographic data, mechanism of injury, Injury Severity Score (ISS), admission vital signs, and associated injuries were abstracted. Additional data regarding management of the aortic injury, including time to intervention if performed, treatment of associated traumatic injuries, and complications and outcomes, were recorded.

All CT scans were reviewed with a faculty trauma radiologist. Aortic injuries were classified as follows: grade I indicated an intimal tear or intramural hematoma, grade II indicated a small pseudoaneurysm $(<50 \%$ of the 


\section{Abbreviations and Acronyms \\ AAST = American Association for the Surgery of Trauma \\ BTAI = blunt traumatic aortic injury \\ $\mathrm{CT}=$ computed tomography \\ ISS $=$ Injury Severity Score \\ SSI $=$ secondary signs of injury \\ TEVAR $=$ thoracic endovascular aortic repair \\ TBI $=$ traumatic brain injury}

aortic circumference), grade III indicated a large pseudoaneurysm $(>50 \%$ of the aortic circumference), and grade IV indicated rupture or transection (Figure 1).

Secondary signs of injury (SSI) on chest CT, defined as pseudocoarctation, mediastinal hematoma with mass effect, and large left hemothorax, were identified and recorded (Figure 2). The presence of a mediastinal hematoma, regardless of size, without mass effect was not considered to represent SSI.

Once the diagnosis of an aortic injury was made, hemodynamically stable patients were treated with $\beta$-blockers, usually intravenous esmolol hydrochloride (INN esmolol). Although there was no rigidly defined algorithm, in general the treatment of the BTAI was based on the severity of the aortic injury, the concomitant associated injuries, and the hemodynamic stability. Treatment of life-threatening injuries took precedence. One of two approaches was chosen to repair BTAI. An open procedure was performed through a left thoracotomy with cardiopulmonary bypass support, or TEVAR was performed with general anesthesia in the operating room with real-time fluoroscopic control. A dedicated chest CT angiogram was used as the follow-up imaging modality.

Data are presented as mean $\pm \mathrm{SD}$. The Student $t$ test was used to compare groups.

\section{RESULTS}

Ninety-seven patients met inclusion criteria. The average age and ISS were $47 \pm 18.8$ years and $38.8 \pm$ 14.6, respectively. Sixty-seven $(69 \%)$ were male. The mechanism of injury included motor vehicle collisions $(69 \%)$, motorcycle or all-terrain vehicle collisions $(11 \%)$, falls $(10 \%)$, pedestrians struck by a vehicle $(8 \%)$, and crush injuries $(1 \%)$. Seventy-eight patients were transported from the field, with the remainder transferred to our facility before operative therapy for BTAI. Associated injuries were common; $34 \%$ had a pelvic fracture, $30 \%$ had traumatic brain injury (TBI), and $23 \%$ required laparotomy (Table 1).

There were 31 grade I injuries, 35 grade II injuries, 24 grade III injuries, and 7 grade IV injuries. Twenty patients $(21 \%)$ were hypotensive (systolic blood pressure $<90 \mathrm{~mm}$ $\mathrm{Hg}$ ) on arrival to our facility. Four patients who had sustained multiple injuries and presented in cardiac arrest were resuscitated but subsequently died of associated injuries. SSI included a large left hemothorax in 7 patients, pseudocoarctation in 15, and a large mediastinal hematoma with mass effect in 26 patients. Overall, 30 patients $(31 \%)$ had SSI, with 13 exhibiting 2 or more SSI findings. Findings of SSI (and multiple SSI) were more common in patients with higher-grade aortic injury (Table 2). Anatomic aortic variants were identified in 39 patients $(40 \%)$. Bovine arch was the most common variant, followed by an anomalous origin of the arch vasculature. There was no correlation between the grade of aortic injury and the incidence of anatomic aortic variants.

Twenty-eight patients with grade I injuries (90\%) were treated medically, and 3 underwent TEVAR. The mortality for grade I injuries was $13 \%$, with no aortic-related mortality. Among those with grade II injuries, 13 patients were managed medically, with the remainder undergoing TEVAR. The mortality for grade II injuries was $20 \%$, with 1 aortic-related death occurring after TEVAR. Of the 24 patients with a grade III BTAI, 4 were managed nonoperatively, 18 underwent TEVAR, and 2 underwent an open procedure. Mortality in this group was $21 \%$. No deaths were the result of the aortic injury or its treatment. Seven patients sustained grade IV injuries, with a $71 \%$ mortality, all the result of the aortic injury. Interestingly, the 4 patients with grade IV injuries who were normotensive on arrival died, whereas 2 of the remaining 3 arriving in shock survived. All 7 of the grade IV injuries were repaired, 5 open and 2 with TEVAR (Table 2).

Stratifying patients by treatment regimen, $45(46 \%)$ were managed medically and $52(54 \%)$ had either an open procedure $(\mathrm{n}=7)$ or TEVAR $(\mathrm{n}=45)$. Among those managed medically, there were 14 deaths $(31 \%)$, all the result of associated injuries, including severe TBI, abdominal injury, or pelvic trauma. Among those managed medically, nonsurvivors had a significantly higher ISS than did survivors $(48.6 \pm 12.8$ vs $33.0 \pm$ $10.8 ; P<.0001)$. There were no aortic-related deaths, ruptures, complications, or emergency interventions among those managed medically.

Fifty-two patients were treated with either TEVAR or an open procedure, with an overall survival of $87 \%$. TEVAR was used in 45 patients (87\%), with a $93 \%$ survival. There were 2 potentially aortic-related mortalities, 1 each among those with grade II and IV lesions. One patient with a previous left internal thoracic artery bypass graft to his left anterior descending coronary artery had a cardiac arrest and died after a very challenging TEVAR procedure in which the left subclavian artery was covered by the stent graft. Another patient with an isolated BTAI had acute renal failure and ventricular fibrillation develop within 24 hours of TEVAR. Neither could be resuscitated. One additional death occurred on hospital day 5 from intra-abdominal sepsis after damage-control laparotomy.

There were 13 procedural complications in 11 patients after TEVAR, for a total complication rate of $24 \%$. These included 3 endoleaks, 3 vascular site complications, and a retained guidewire in 5 patients who required 7 additional interventions, including 1 open aortic repair on bypass. 


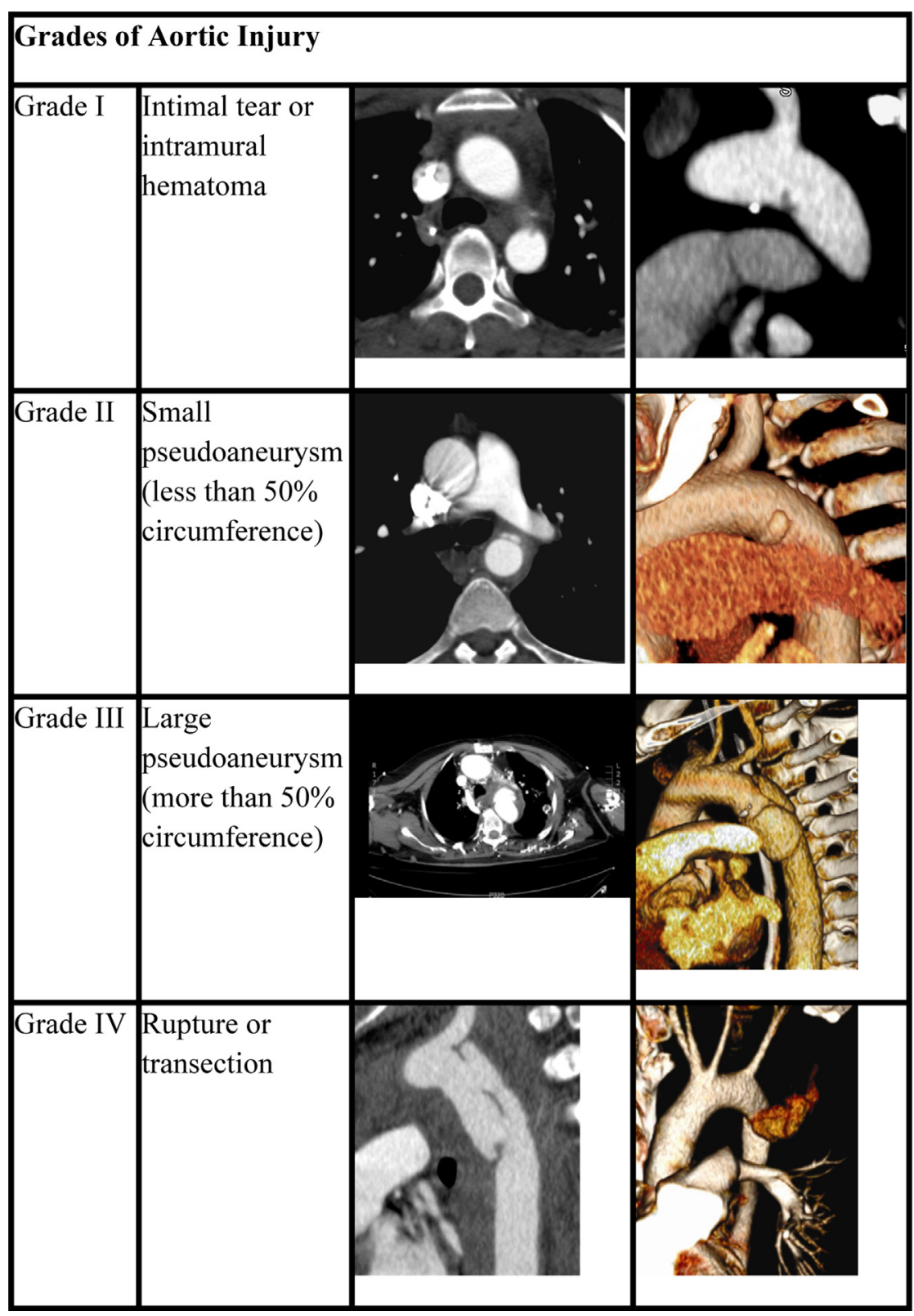

FIGURE 1. Computed tomographic imaging demonstrating the grades of aortic injury.

Six additional patients had observed complications. Thus major aortic complications (death or reintervention) occurred in 7 patients, or $7.1 \%$ of the total patients and $15 \%$ of those treated with TEVAR.

A total of 7 open repairs (14\%) were performed, with 4 deaths, all of whom presented with active bleeding from aortic rupture. Operative management included cardiopulmonary bypass for patients with grade IV injury (not in extremis) and 2 with grade III. One patient required reexploration for postoperative bleeding, and one had drainage of a retained hemothorax with a chest tube; no patient with open treatment had either postoperative paraplegia or neurologic morbidity.
Twenty-three $(74 \%)$ of the 31 surviving medically managed patients were followed up an average of 3.8 months. Eleven grade I injuries resolved. Five grade I and 5 grade II injuries were unchanged, and 1 patient with grade II injury subsequently underwent an elective repair. Two patients in grade I had small increases in their injuries but did not require intervention. There were no aortic-related deaths, ruptures, complications, or emergency interventions during follow-up among the patients managed medically. Of the 41 patients discharged after TEVAR, $39(95 \%)$ had follow-up for an average of 5.8 months with at least 1 postoperative CT angiogram. No additional procedures were required, and no complications or deaths occurred. 


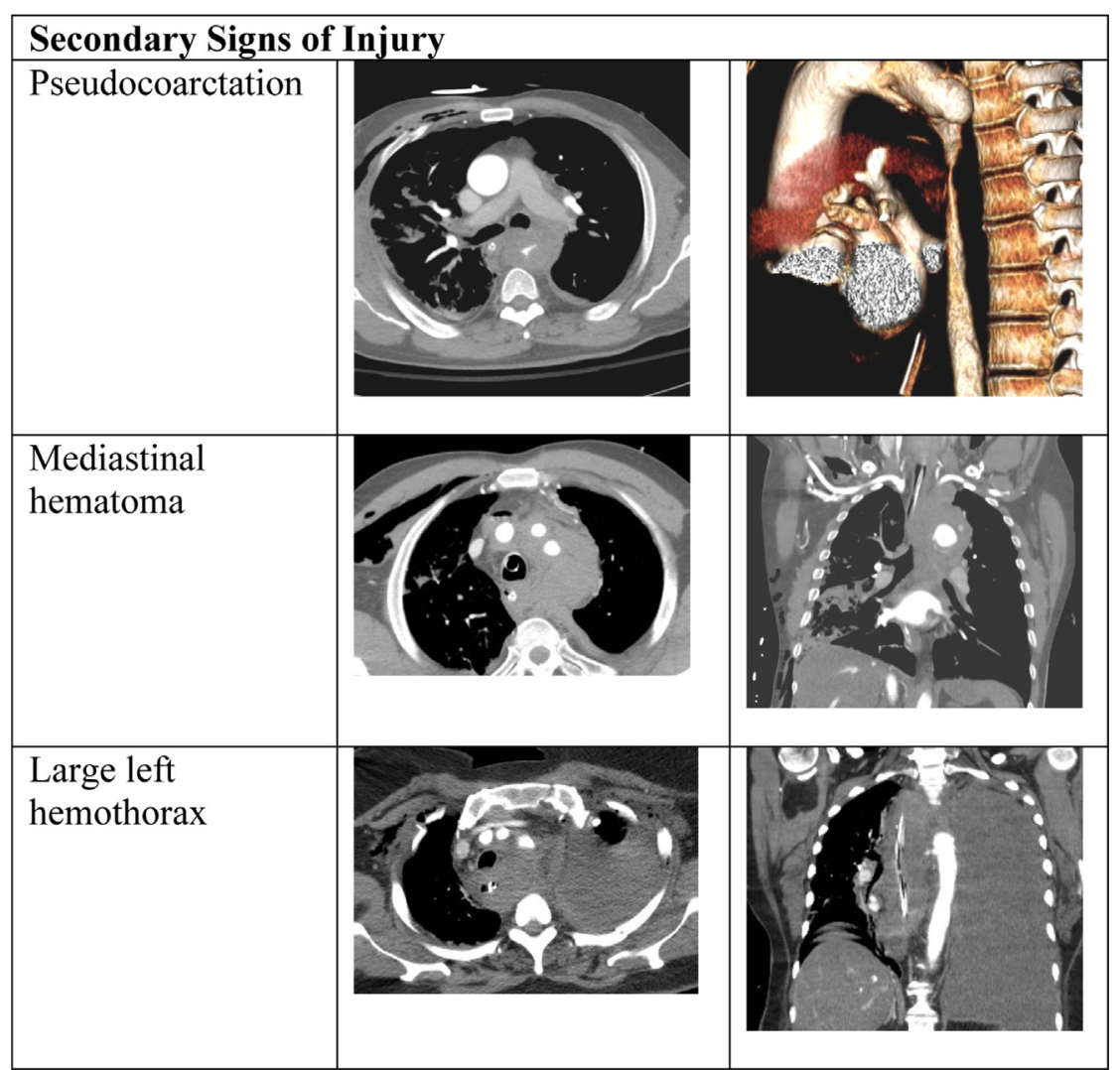

FIGURE 2. Chest computed tomographic imaging demonstrating secondary signs of injury. Note the mediastinal hematoma with mass effect.

\section{DISCUSSION}

In 1958, Parmley and colleagues ${ }^{1}$ defined the natural history of untreated blunt aortic injury. Emergency open repair became the standard. Twenty years later, $\beta$-blockers began to be used to decrease aortic shear forces. Surgeons learned that these drugs could be used to delay repair in selected patients and continued until the patient was deemed stable for definitive repair. ${ }^{2}$ As clinical experience accumulated, some patients had repair delayed for days or even weeks, and this practice of delayed repair was shown to be associated with improved outcomes. The large 1997 prospective American Association for the Surgery of Trauma (AAST) series ${ }^{3}$ provided an important historical snapshot in time. All patients underwent emergency open repair. Overall mortality was greater than $30 \%$, and paraplegia occurred in approximately $9 \%$ of patients.

Aortic stent-grafting to treat BTAI was first described in $1997^{4}$ and quickly became an attractive alternative to open repair. In 2008, Demetriades and associates ${ }^{5}$ performed another prospective AAST multi-institutional trial. Sixtyfive percent of patients were treated endovascularly. Those treated with TEVAR had a statistically lower mortality. Endovascular repair was clearly becoming a viable option. A follow-up study from the AAST group indicated that delayed repair was associated with improved survival despite longer intensive care unit stays. ${ }^{6}$

Neither of these AAST studies, however, addressed variability of aortic injury. Only a minority of patients presented with frank rupture. Most had less severe injuries, ranging from pseudoaneurysm to intimal disruption. Other authors

TABLE 1. Demographic data

\begin{tabular}{lc}
\hline \multicolumn{1}{c}{ Total patients } & $\mathbf{9 7}$ \\
\hline Male & $67(69 \%)$ \\
Age $(\mathrm{y}$, mean $\pm \mathrm{SD})$ & $47 \pm 18.8$ \\
ISS (mean $\pm \mathrm{SD})$ & $38.8 \pm 14.6$ \\
Injury event & \\
$\quad$ MVC & $67(69 \%)$ \\
MCC & $11(11.3 \%)$ \\
Fall & $10(10.3 \%)$ \\
Pedestrian struck & $8(8.2 \%)$ \\
Crush & $1(1 \%)$ \\
Field transport & $78(80.4 \%)$ \\
Pelvic fracture & $33(34 \%)$ \\
TBI & $29(30 \%)$ \\
Laparotomy & $22(23 \%)$ \\
\hline All data are number and percentage of patients except as indicated. $I S S$, Injury \\
Severity Score; $M V C$, motor vehicle collision; $M C C$, motorcycle or all-terrain vehicle \\
collision; $T B I$, traumatic brain injury; $S D$, standard deviation.
\end{tabular}


TABLE 2. Treatment modality and outcome by grade of aortic injury

\begin{tabular}{|c|c|c|c|c|c|c|c|c|c|c|}
\hline & \multirow[b]{3}{*}{$\begin{array}{c}\text { Total } \\
(\mathbf{N}=97)\end{array}$} & \multicolumn{9}{|c|}{ Grade } \\
\hline & & \multicolumn{2}{|c|}{$\mathbf{I}(\mathbf{n}=\mathbf{3 1})$} & \multicolumn{2}{|c|}{ II $(\mathbf{n}=\mathbf{3 5})$} & \multicolumn{3}{|c|}{ III $(n=24)$} & \multicolumn{2}{|c|}{ IV $(n=7)$} \\
\hline & & $\begin{array}{l}\text { Medical } \\
(\mathbf{n}=\mathbf{2 8})\end{array}$ & $\begin{array}{c}\text { TEVAR } \\
(\mathbf{n}=3)\end{array}$ & $\begin{array}{c}\text { Medical } \\
(n=13)\end{array}$ & $\begin{array}{l}\text { TEVAR } \\
(n=22)\end{array}$ & $\begin{array}{c}\text { Medical } \\
(n=4)\end{array}$ & $\begin{array}{l}\text { TEVAR } \\
(\mathrm{n}=18)\end{array}$ & $\begin{array}{c}\text { Open } \\
(n=2)\end{array}$ & $\begin{array}{l}\text { TEVAR } \\
(\mathrm{n}=2)\end{array}$ & $\begin{array}{r}\text { Open } \\
(n=5)\end{array}$ \\
\hline ISS (mean \pm SD) & $38.8 \pm 14.6$ & \multicolumn{2}{|c|}{$33.1 \pm 9.9$} & \multicolumn{2}{|c|}{$38.8 \pm 14.2$} & \multicolumn{3}{|c|}{$41.5 \pm 15.2$} & \multicolumn{2}{|c|}{$57.8 \pm 18.9$} \\
\hline Aortic-related mortality & & 0 & 0 & 0 & 1 & 0 & 0 & 0 & 1 & 4 \\
\hline Reintervention & & 0 & 0 & 0 & 1 & 0 & 3 & 1 & 3 & 1 \\
\hline Survival & $76(78.4 \%)$ & 24 & 3 & 7 & 21 & 0 & 17 & 2 & 1 & 1 \\
\hline SSI & & \multicolumn{2}{|c|}{1} & \multicolumn{2}{|c|}{6} & & 17 & & \multicolumn{2}{|c|}{6} \\
\hline
\end{tabular}

Data represent number of patients unless otherwise noted. TEVAR, Thoracic endovascular aortic repair; ISS, Injury Severity Score; SSI, secondary signs of injury; SD, standard deviation.

contended that early TEVAR was a wise strategy for at least some aortic injuries. ${ }^{7,8}$

As CT technology evolved, smaller injuries that had never been detected in the past started being diagnosed. On the basis of the assertion that all aortic injuries required repair early on, many of these underwent TEVAR. Yet clinicians began wondering whether these patients with small injuries, who might have normal chest radiographs and minimal or no mediastinal hemorrhage, really required operative therapy of any kind. Although there have been various reports of minor aortic injuries managed medically without any adverse outcomes, an exact definition of minor or minimal aortic injury is rather ambiguous. Malhotra and associates ${ }^{9}$ defined minor aortic injury as an intimal flap less than $1 \mathrm{~cm}$ with no significant mediastinal hematoma. The Society of Vascular Surgery ${ }^{8}$ identified an intimal injury as a minimal injury not requiring repair, suggesting repair for all other injuries including intramural hematomas and any aortic contour abnormality. According to Gavant, ${ }^{10}$ a minimal aortic injury included a pseudoaneurysm less than $1 \mathrm{~cm}$ with a small intimal flap. Our institution previously described minimal aortic injury as one with a low risk of rupture or no obvious detrimental impact on the patient, ${ }^{11}$ whereas another institution defined a minimal injury as one "that appeared to be nonthreatening." 12

Because CT scans are now capable of defining the architecture of aortic injuries, a grading system is needed to stratify injury severity and identify patients who need urgent or emergency therapy. In addition, it should identify those patients for whom only medical management is needed. Several grading scales have been described. We agree with those that consider pseudoaneurysm size an important factor and discriminate between large and small pseudoaneurysms. $^{10,12,13}$ The Stanford group also has distinguished among intimal injury, intraluminal filling defect, and mural injury ${ }^{13}$; however, we have combined all these into the grade I category because there were often only subtle differences distinguishing them on our CT scans and they were all often managed nonoperatively. The Presley grading system defines a small pseudoaneurysm on the basis of absolute size rather than with respect to the baseline size of the aorta.
The system also has subgroups for secondary findings of BTAI, such as mediastinal hematoma or great vessel involvement. $^{10}$

In our classification, we chose not to increase the grade of injury on the basis of arch or great vessel involvement. Instead, we identified other secondary signs of injury that would upgrade an injury, including mediastinal hematoma with mass effect, pseudocoarctation, and large left hemothorax. On the basis of specific institutional experience, Azizzadeh and coworkers ${ }^{14}$ in 2009 classified aortic injury into 4 grades, a grading scheme subsequently adopted for clinical guidelines by the Society of Vascular Surgery and closely resembling other classification schemes. ${ }^{15}$ They distinguished between an intimal injury and intramural hematoma, as did Caffarelli and colleagues, ${ }^{13}$ but classified all pseudoaneurysms as grade III. The Starnes group ${ }^{15}$ also classified all pseudoaneurysms as grade 3 , but still noted that none of their patients with a pseudoaneurysm who did not undergo repaired died of their BTAI or had an increase in the pseudoaneurysm.

The current series of 97 patients represents a large singleinstitution experience in a high-volume trauma center. More than two-thirds (66 patients) had relatively low-grade injuries (grade I or II), and 41 of these patients were successfully treated with medical management alone. Three of the patients with 31 grade I injuries $(10 \%)$ underwent repair with TEVAR. We would likely treat these injuries with medical management alone today. As aortic injury worsened, larger percentages of patients were treated with operative repair, including 22 of 35 with grade II injuries (63\%) and 20 of 24 with grade III injuries $(83 \%)$. All 7 patients with grade IV injuries were treated with either open repair or TEVAR.

Because it requires a significant amount of force to cause aortic injury, it is not a surprise that these patients had multiple severe injuries, with a mean ISS of almost 40. It is also not a surprise that ISS increased as aortic injury worsened. Even in multiply injured patients, all deaths among those managed medically were related to associated injuries. None died directly of aortic injury. Nonsurvivors treated nonoperatively had a higher ISS than did survivors, 
reinforcing the concept that in patients with multiple injuries, emergency treatment must be determined by the most life-threatening injury, and that the aortic injury may not be the highest priority and may not be actively treated medically if the patient's condition is too unstable. In our experience, nonsurvivors with grade II and III injury were in unstable condition on arrival, contraindicating $\beta$-blockade, and ultimately died of catastrophic TBI, intra-abdominal bleeding, or both. Our practice for TBI management is to maintain a cerebral perfusion pressure of at least $55 \mathrm{~mm} \mathrm{Hg}$ and this is often compatible with our hemodynamic goals for BTAI. Patients with severe TBI and uncontrolled intracranial pressures are usually not candidates for aortic repair because of their neurologic instability, which reinforces the concept that BTAI may not be the most life-threatening injury or highest priority. Our data also underscore that TEVAR is an operative procedure that carries complications. Morbidity was $24 \%$ among those treated with TEVAR, including 5 patients who had 7 reinterventions. There were 2 perioperative deaths, including that of a patient with a previous bypass graft from the left internal thoracic artery to the left anterior descending coronary artery who died after his subclavian artery was covered during a difficult TEVAR case. These complex patients with a previous left internal thoracic artery to left anterior descending coronary artery graft are well known to us to be quite challenging, and they often require additional intervention. ${ }^{16}$ Another patient had acute renal failure develop within 24 hours of TEVAR and then sustained a ventricular fibrillatory arrest.

In the 2008 AAST study, ${ }^{5}$ procedural complications after TEVAR were $20 \%$, and earlier data from our institution had a $15 \%$ procedural complication rate. ${ }^{17}$ In that series, a single surgeon performed all TEVARs. In our current practice, multiple surgeons perform aortic repair. It is unclear whether physician variability played a role in the morbidity and or mortality of our current series. Regardless, given the success with medical management, it is important to weigh the necessity of operative intervention, whether that is performed open or by TEVAR.

Our current grading scheme and basic treatment algorithm offers a simplified approach to the acute management of aortic injury, with a goal of identifying those patients requiring emergency operative treatment, distinguishing them from those who can be medically managed. We believe that not all pseudoaneurysms are the same. Large, nearly circumferential pseudoaneurysms do not have the same risk of rupture as do small pseudoaneurysms, and they should not all be classified within the same group of contour abnormalities. The presence of SSI, more prevalent as overall aortic injury worsens, can help identify those requiring immediate therapy.

Selective nonoperative management of BTAI has been adopted by some for very severely injured patients, whereas others have proposed medical management alone for minimal intimal injuries. Our results demonstrate successful medical treatment of aortic injury including both grade I intimal injury and grade II pseudoaneurysm. Even those patients with grade III aortic injury did not have rupture or die of the aortic injury but rather died of severe associated injuries. Our hemodynamic goals for medical management are similar to our approach toward type B aortic dissections and attempt to reduce aortic wall shear stress. Both $\beta$-blockade and other antihypertensive agents are administered to maintain a systolic blood pressure between 100 and $120 \mathrm{~mm} \mathrm{Hg}$, mean arterial pressure at or below $80 \mathrm{~mm} \mathrm{Hg}$, and heart rate between 60 and 80 beats/min. This is similar to the results reported by Caffarelli and colleagues. ${ }^{13}$ They reported successful nonoperative management of 27 patients, including 19 patients with pseudoaneurysms. Our data show similar success, but in a patient population with a higher ISS (38.8 vs 32.2 ) and more patients admitted from the field, thereby reducing potential selection bias of patients transferred hours or days after injury. These results are, however, based on short-term data and limited follow up. Long-term observation is still required to delineate the natural history and evolution of these medically managed injuries. There are some data to suggest that unrepaired injuries develop into chronic pseudoaneurysms, which eventually require repair or may even rupture months or years later. ${ }^{18,19}$ An essential component of long-term follow-up includes serial CT scan imaging. This includes serial imaging on initial admission that demonstrates a stable or improving traumatic lesion. Outpatient CT scans would be planned for 1,6 , and 12 months after a grade I injury, with an additional scan at 3 months for a grade II injury. Subsequent imaging would be annual, unless the condition resolved or evolved into a lesion requiring repair.

Our experience, and that of others, suggests that acute aortic rupture is most likely to occur within the first 4 to 6 hours after injury. ${ }^{20}$ Several studies of early intensive medical management have reported catastrophic complications of aortic rupture after 4 to 8 hours to be rare, so long as strict blood pressure and shear stress controls are maintained with $\beta$-blockers. ${ }^{19,21-23}$ The ability to delay repair safely, whether for a period of months or years, should not be construed as a failure of nonoperative management. Patients may undergo a future elective repair at an aortic center of excellence, decreasing the associated morbidity and mortality risks of an emergency aortic operation.

One of the unanswered questions about the use of TEVAR for BTAI is long-term outcome. Although the shortterm follow-up is encouraging, with no complications or additional procedures required after discharge, the longterm follow up is poor. The ability to monitor the fate of the graft for decades is essential. This is particularly true 
for younger patients with an anticipated normal life span. We were able to get short-term follow-up on 23 of the patients managed medically. Eleven of the 28 grade I injuries resolved. An additional 5 showed no change, as did 5 grade II injuries. Only 1 patient with a grade II injury ultimately underwent an elective operative repair, which was done at the surgeon's discretion because the injury remained stable. This seems to underscore the safety of medical management, at least for low-grade injuries, and emphasizes the need for improved long-term follow-up, because it is similar to the treatment regimen for medically managed type B aortic dissection. Only after the patient has been seen in follow-up with serial imaging would we potentially consider, on a case-by-case basis, modestly liberalizing the blood pressure goals.

We conclude that not all patients with BTAI require repair. Patients with grade IV injuries are often moribund and require emergency procedures, which are associated with a high mortality. Grade III injuries with SSI should be urgently repaired. Those without SSI may undergo delayed repair after initial medical management. Grade I and II injuries are amenable to nonoperative medical management alone. Only some injuries resolve, but the risk of late rupture seems very small. Patients with concomitant central nervous system injury, for whom antihypertensive therapy or $\beta$-blockers might be deleterious, or those with SSI suggesting a greater risk of rupture, may also be candidates for repair. TEVAR, although an attractive option, is associated with a real risk of complication. Among patients treated medically, mortality seems related to associated injuries and overall injury severity rather than to the aortic injury. Finally, aortic variants such as the bovine arch may be a risk factor for BTAI, but more study is necessary to understand their significance.

\section{References}

1. Parmley LF, Mattingly TW, Manion WC, Jahnke EJ Jr. Nonpenetrating traumatic injury of the aorta. Circulation. 1958;17:1086-101.

2. Akins CW, Buckley MJ, Daggett W, McIlduff JB, Austen WG. Acute traumatic disruption of the thoracic aorta: a ten year experience. Ann Thorac Surg. 1981;31: 305-9.

3. Fabian TC, Richardson JD, Croce MA, Smith JS Jr, Rodman G Jr, Kearney PA, et al. Prospective study of blunt aortic injury: Multicenter trial of the American Association for the Surgery of Trauma. J Trauma. 1997;42:374-80; discussion 380-3

4. Kato N, Dake MD, Miller DC, Semba CP, Mitchell RS, Razavi MK, Kee ST. Traumatic thoracic aortic aneurysm: treatment with endovascular stent-grafts. Radiology. 1997;205:657-62.

5. Demetriades D, Velmahos GC, Scalea TM, Jurkovich GJ, Karmy-Jones R, Teixeira PG, et al. Operative repair or endovascular stent graft in blunt traumatic thoracic aortic injuries: results of an American Association for the Surgery of Trauma Multicenter Study. J Trauma. 2008;64:561-70; discussion $570-71$.

6. Demetriades D, Velmahos GC, Scalea TM, Jurkovich GJ, Karmy-Jones R, Teixeira PG, et al. Blunt traumatic thoracic aortic injuries: early or delayed repair-results of an American Association for the Surgery of Trauma prospective study. J Trauma. 2009;66:967-73.

7. Agostinelli A, Saccani S, Borrello B, Nicolini F, Larini P, Gherli T. Immediate endovascular treatment of blunt aortic injury: our therapeutic strategy. J Thorac Cardiovasc Surg. 2006;131:1053-7.
8. Lee WA, Matsumura JS, Mitchell RS, Farber MA, Greenberg RK, Azizzadeh A, et al. Endovascular repair of traumatic thoracic aortic injury: clinical practice guidelines of the Society for Vascular Surgery. J Vasc Surg. 2011;53:187-92.

9. Malhotra AK, Fabian TC, Croce MA, Weiman DS, Gavant ML, Pate JW. Minimal aortic injury: a lesion associated with advancing diagnostic techniques. $J$ Trauma. 2001;51:1042-8

10. Gavant ML. Helical CT grading of traumatic aortic injuries. Impact on clinical guidelines for medical and surgical management. Radiol Clin North Am. 1999; 37:553-74.

11. Neschis DG, Scalea TM, Flinn WR, Griffith BP. Blunt aortic injury. $N$ Engl $J$ Med. 2008;359:1708-16.

12. Paul JS, Neideen T, Tutton S, Milia D, Tolat P, Foley D, et al. Minimal aortic injury after blunt trauma: selective nonoperative management is safe. J Trauma. 2011;71:1519-23.

13. Caffarelli AD, Mallidi HR, Maggio PM, Spain DA, Miller DC, Mitchell RS Early outcomes of deliberate nonoperative management for blunt thoracic aortic injury in trauma. J Thorac Cardiovasc Surg. 2010;140:598-605.

14. Azizzadeh A, Keyhani K, Miller CC III, Coogan SM, Safi HJ, Estrera AL. Blunt traumatic aortic injury: initial experience with endovascular repair. J Vasc Surg. 2009;49:1403-8

15. Starnes BW, Lundgren RS, Gunn M, Quade S, Hatsukami TS, Tran NT, et al. A new classification scheme for treating blunt aortic injury. J Vasc Surg. 2012;55: 47-54.

16. Rabin J, Chi A, Neschis DG, Griffith BP, Scalea TM. Blunt aortic injury in a patient with prior coronary artery bypass surgery. Ann Thorac Surg. 2012;93:294-6.

17. Neschis DG, Moainie S, Flinn WR, Scalea TM, Bartlett ST, Griffith BP. Endog raft repair of traumatic aortic injury - a technique in evolution: a single institution's experience. Ann Surg. 2009;250:377-82.

18. Mosquera VX, Marini M, Lopez-Perez JM, Muñiz-Garcia J, Herrera JM, Cao I, et al. Role of conservative management in traumatic aortic injury: comparison of long-term results of conservative, surgical, and endovascular treatment. J Thorac Cardiovasc Surg. 2011;142:614-62.

19. Finkelmeier BA, Mentzer RM Jr, Kaiser DL, Tegtmeyer CJ, Nolan SP. Chronic traumatic thoracic aneurysm. Influence of operative treatment on natural history: an analysis of reported cases, 1950-1980. J Thorac Cardiovasc Surg. 1982;84: 257-66.

20. Burkhart HM, Gomez GA, Jacobson LE, Pless JE, Broadie TA. Fatal blunt aortic injuries: a review of 242 autopsy cases. J Trauma. 2001;50:113-5.

21. Pate JW, Gavant ML, Weiman DS, Fabian TC. Traumatic rupture of the aortic isthmus: program of selective management. World J Surg. 1999;23:59-63.

22. Fabian TC, Davis KA, Gavant ML, Croce MA, Melton SM, Patton JH Jr, et al Prospective study of blunt aortic injury: helical CT is diagnostic and antihypertensive therapy reduces rupture. Ann Surg. 1998;227:666-76; discussion 676-7.

23. Lang JL, Minei JP, Modrall JG, Clagett GP, Valentine RJ. The limitations of thoracic endovascular aortic repair in altering the natural history of blunt aortic injury. J Vasc Surg. 2010;52:290-7; discussion 297

\section{Discussion}

Thomas E. MacGillivray (Boston, Mass). I thank the Association for the opportunity to discuss this presentation. I congratulate Dr Rabin on his excellent presentation and thank him for providing me a copy of the manuscript in advance.

I am sure that there are many surgeons in the audience who remember those days when all victims of blunt trauma who had a widened mediastinum were whisked away for an aortogram. The small percentage of patients who actually turned out to have an aortic injury were taken to the operating room for emergency aortic repair regardless of their other life-threatening injuries.

In the 1980s, Akins and Hilgenberg were the first to report the then very controversial practice of delaying aortic operation with aggressive anti-impulse therapy for days, weeks, and even months. Subsequently, centers reported that surgical, later replaced by endovascular, repair could safely be delayed while the other life-threatening injuries either declared themselves or were successfully managed. 
Rabin and colleagues have presented their contemporary series of 97 patients with blunt traumatic aortic injuries. With high-resolution CT angiography, they have developed a grading system that not only confirms the diagnosis of aortic injury but also helps guide the management of these complicated patients.

Their group has recognized that blunt traumatic aortic injury is in fact a spectrum of disease. The ultimate fate of these patients is usually determined by the other organ injuries and not the aortic injury. They have also reinforced the principle that definitive aortic repair can be safely delayed while the other injuries are managed. They have now taken a further step, and perhaps a leap, in suggesting that some of these injuries should be managed without any repair at all. I will limit my questions to two.

Dr Rabin, in your conclusions, you have recommended nonoperative management rather than delayed operation as definitive therapy for grade I and II injuries. For grade I injuries, I suspect that nonoperative management has unknowingly been practiced for years, given that many of these injuries once went undiagnosed because of the limitations in imaging of the time. In your nonrandomized patient series, almost two-thirds of patients with grade II injuries underwent TEVAR, and they ultimately had a 95\% overall survival. Among the nonoperatively managed patients with grade II injuries, there was a $50 \%$ mortality, although none of the deaths were attributed to aortic injuries.

So in the absence of a prospective protocol, what were the factors that determined whether a patient was managed by TEVAR or medical management alone? Do you think that this selection bias was at all important in potentially averting aortic-related morbidity and mortality?

Dr Rabin. Thank you very much, Dr MacGillivray, for your review and comments and excellent questions.

With regard to the grade I injuries, we agree that probably a lot of these were never detected in the past, and it is only with the modern CT scanners that we find these. Thus by default many such injuries have resolved without our even knowing. With regard to grade II injuries, that is a more difficult area even for ourselves. I think this discrepancy that we see between those that were repaired and those that weren't reflects the wide provider variability. We believe this was one of the primary factors in determining who underwent repair and who didn't. Other concomitant injuries and that many patients are lost to follow-up were other factors in the decision to repair.

Moving forward, we are trying to put together a dedicated aortic group to regularly review the data and get a better protocol-driven approach to these difficult patients. Even though we may not operatively repair these injuries, it is still not the end of the story. For patients with even a small pseudoaneurysm, this is not definitive treatment and such patients require medical treatment with $\beta$-blockers and continuous follow-up with serial imaging to determine the natural course of the injury.

Dr MacGillivray. Finally, your follow-up period for the surviving medically managed patients was, on average, only 3.8 months. Among the patients with grade 2 injury, only 7 of 35 , or $20 \%$, were actually managed nonoperatively. So in the absence of randomized data, with only a minority of patients receiving nonoperative management and without longer follow-up, do you consider your analysis robust enough, and do you feel really confident enough in recommending to us nonoperative management in these cases?

Dr Rabin. I think that in these cases we have found that the risks of repair are not benign. With 2 of 45 patients dying and 5 having major reinterventions, this needs to be weighed against the risk of rupture, which is very rare in our study and in other studies that also assess late rupture. As we monitor these patients, it has to be taken on a case-by-case basis. We look at their other findings within the mediastinum, whether there is any evidence of SSI, such as significant hematoma, or in cases of head trauma, if we could not provide adequate $\beta$-blockade for these patients, we would likely have a lower threshold for repair. So, while strongly considering nonoperative management in these grade II patients, it is not such a simple approach. 